\title{
High-Performance SVPWM-VCIM Drive with Adaptive Neuro-Fuzzy Speed Controller
}

\author{
Rajesh Kumar, R. A. Gupta, and Rajesh S. Surjuse, Member, IACSIT
}

\begin{abstract}
This paper presents a novel space vector pulse-width modulated vector controlled induction motor drive with adaptive neuro-fuzzy based speed controller. SVPWM is superior to other PWM schemes from the view point of dc-link voltage utilization and current harmonics. The proposed neuro-fuzzy controller incorporates fuzzy logic algorithm with a five-layer artificial neural network (ANN) structure. The conventional PI controller is replaced by Adaptive Neuro-Fuzzy Inference System (ANFIS), which tunes the fuzzy inference system with hybrid learning algorithm. This makes fuzzy system to learn. The performance of the proposed neuro-fuzzy based SVPWM-VCIM drive is investigated at different operating conditions. The results of the proposed controller are also compared to those obtained by a conventional PI controller. The simulation study indicates robustness and suitability of drive for high performance drive applications.
\end{abstract}

Keywords-Adaptive Neuro-Fuzzy Inference System (ANFIS), Artificial Neural Network (ANN), Space Vector Pulse-Width Modulation (SVPWM), hybrid learning algorithm, Vector Controlled Induction Motor (VCIM).

\section{INTRODUCTION}

Space Vector Pulse Width Modulation (SVPWM) [1] has become one of the most popular PWM methods for three phase inverters because it is more easily realized digitally, outputs higher voltage (as modulation index $m=2 / \sqrt{3}$ ) than regular sinusoidal PWM under the same dc link voltage and less harmonics in the output voltage. Similarly, vector controlled induction motor (IM) drive is a very accepted method for high performance system response. This method employs the conventional Proportional - Integral (PI), Proportional - Integral - Derivative (PID) controller or their adaptive versions, for variable speed drive applications. However, the design of these controllers depends on exact mathematical model with accurate parameters. The difficulties of obtaining the exact parameters of the induction motor leads to cumbersome design approach. Also the conventional fixed gain PI and PID controllers are very sensitive to disturbances, parameter variations and system

Manuscript received July 1, 2009.

Rajesh Kumar is Reader with the Department of Electrical Engineering, Malaviya National Institute of Technology (MNIT), Jaipur, India. Email: rkumar.ee@gmail.com.

R. A. Gupta is Professor with the Department of Electrical Engineering, Malaviya National Institute of Technology (MNIT), Jaipur, India.

Email:rag_mnit@rediffmail.com.

Rajesh S. Surjuse is Research Scholar with the Department of Electrical Engineering, Malaviya National Institute of Technology (MNIT), Jaipur, India. Phone: 91-09887807122, Email: surjusemnit@rediffmail.com. non-linearity. On the other hands, the design of intelligent controllers based on Artificial Intelligence (AI) does not need the exact mathematical model of the system. Therefore Artificial Neural Network (ANN) and Fuzzy Logic Control (FLC) demands special attention for speed control of high performance IM drives.

Fuzzy Logic Controller yields superior and faster control [2]-[3], without the need of accurate mathematical model of the system and works well for complex, non-linear, multi-dimensional system with parameter variations or with less precise signals. The main design problem lies in the determination of consistent and complete rule set and shape of the membership functions. A lot of trial and error has to be carried out to obtain the desired response which is time consuming. On the other hand, ANN alone is insufficient if the training data are not enough to take care of all the operating modes.

Adaptive Neuro-Fuzzy Inference System (ANFIS) is used as an intelligent tool to design FLC [4]-[10]. It helps to generate and optimize membership functions as well as the rule base from the simple data provided. ANFIS combine the learning power of neural network with knowledge representation of fuzzy logic. This paper presents a novel speed control scheme for SVPWM-VCIM drive based on Neuro-fuzzy controller (NFC). The proposed NFC is adapted by a hybrid learning algorithm in order to minimize the square of the error between desired and actual output. A 5-layer ANN structure is utilized to train the parameters of the FLC, which eliminates unwanted trial and error as was in the case for a conventional fuzzy logic control. A complete simulation model for SVPWM-VCIM drive incorporating the proposed NFC is developed. The performance of the proposed NFC based SVPWM-VCIM drive is investigated at different operating conditions. A comparison is made with the conventional PI speed controller response. Section II presents Space Vector PWM inverter for induction motor drive. Section III presents the mathematical modeling of IM and vector control scheme. Section IV presents the design aspects of proposed NFC [11]-[12]. Section V and VI presents the performance evaluation and conclusion respectively.

\section{SPACE Vector PWM InVERTER}

PWM control of the inverter switches requires to synthesize the desired reference stator voltage space vector in an optimum manner with the following objectives [1]:

1) A constant switching frequency $f_{s}$. 
2) Smallest instantaneous deviation from its reference value.

3) Maximum utilization of the available dc-bus voltages.

4) Lowest ripple in the motor current and

5) Minimum switching loss in the inverter.

The above conditions are generally met if the average voltage vector is synthesized by means of the two instantaneous basic non-zero voltage vector that form the sector (in which the average voltage vectors to be synthesized lies) and both the zero voltage vectors, such that each transition causes change of only one switch status to minimize the inverter switching loss.

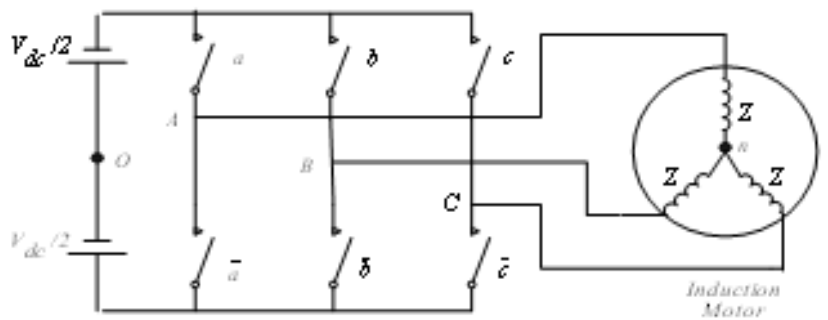

Figure.1 Three phase voltage source inverter

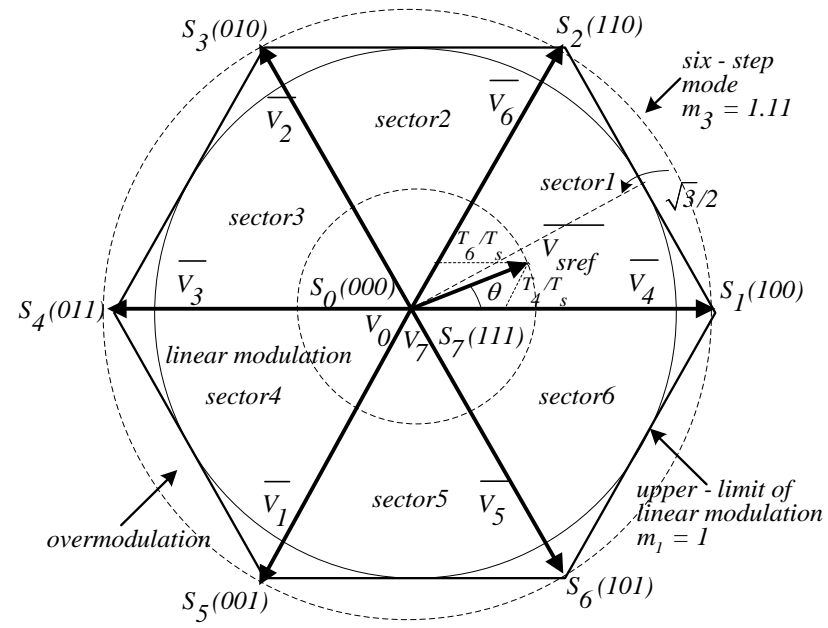

Figure.2 Space vector diagram of the available switching vectors.

In terms of the instantaneous stator phase voltages, the stator space voltage vector is

TABLE I

\begin{tabular}{|c|c|c|c|c|c|c|}
\hline \multicolumn{7}{|c|}{ SUMMARY OF INVERTER SWITCHING STATES } \\
\hline $\begin{array}{l}\text { Voltage } \\
\text { vector }\end{array}$ & $S W_{A}$ & $S W_{B}$ & ${ }^{S W_{C}}$ & $v_{a n}$ & $v_{b n}$ & $v_{c n}$ \\
\hline$V_{0}$ & 0 & 0 & 0 & 0 & 0 & 0 \\
\hline$\overline{V_{1}}$ & 0 & 0 & 1 & $-V_{d c^{\prime 3}}$ & $-V_{d c^{13}}$ & $2 V_{d c} / 3$ \\
\hline$\overline{V_{2}}$ & 0 & 1 & 0 & $-V_{d c}{ }^{13}$ & $2 V_{d c} / 3$ & $-V_{d c} / 3$ \\
\hline$\overline{V_{3}}$ & 0 & 1 & 1 & $-2 V_{d c} / 3$ & $V_{d c^{13}}$ & $V_{d c^{13}}$ \\
\hline$V_{4}$ & 1 & 0 & 0 & $2 V_{d c} / 3$ & $-V_{d c} / 3$ & $-V_{d c} / 3$ \\
\hline$\overline{V_{5}}$ & 1 & 0 & 1 & $V_{d c^{13}}$ & $-2 V_{d c}{ }^{/ 3}$ & $V_{d c^{13}}$ \\
\hline$\overline{V_{6}}$ & 1 & 1 & 0 & $V_{d c^{13}}$ & $V_{d c} / 3$ & $-2 V_{d c^{13}}$ \\
\hline$\overline{V_{7}}$ & 1 & 1 & 1 & 0 & 0 & 0 \\
\hline
\end{tabular}

$" 0 "=$ off, " $1 "=$ on

$\overline{v_{s}}(t)=v_{a}(t) e^{j 0}+v_{b}(t) e^{j 2 \pi / 3}+v_{c}(t) e^{j 4 \pi / 3}$

Assuming the stator neutral as a reference ground

$v_{a}=v_{a n}+v_{n} ; v_{b}=v_{b n}+v_{n} ; v_{c}=v_{c n}+v_{n} ;$

Also

$e^{j 0}+e^{j 2 \pi / 3}+e^{j 4 \pi / 3}=0$

The instantaneous stator voltage space vector can be written in terms of the inverter output voltage as in (4).

$\bar{v}_{s}(t)=v_{a n} e^{j 0}+v_{b n} e^{j 2 \pi / 3}+v_{c n} e^{j 4 \pi / 3}$

Fig.1. shows three phase voltage source inverter with induction motor drive.

The inverter has six states when a voltage is applied to the motor and two states ( $S_{0}$ and $S_{7}$ ) when the motor is shorted through the upper or lower switch resulting in zero volts being applied to the motor. The six vectors including the zero voltage vectors can be expressed geometrically as shown in Fig. 2. Table I depicts summary of inverter switching states. SVPWM seeks to average out the adjacent vectors for each sector. Using the appropriate PWM signals a vector is produced that transitions smoothly between sectors and thus provide sinusoidal line to line voltages to the motor. In order to generate the PWM signals that produce the rotating vector, formulae must be derived to determine the PWM time intervals for each sector. Fig. 3. shows the pulse patterns generated by space vector modulation in sector 1 .

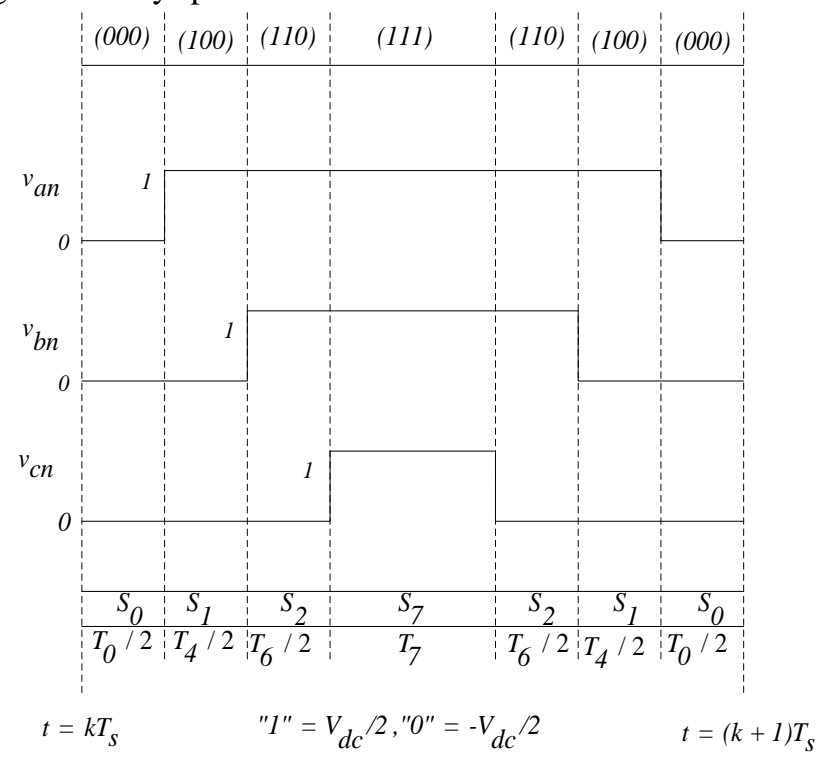

Figure.3 Pulse patterns generated by space vector modulation in sector 1

The above space vector pulse-width modulation can be carried out by comparing control voltages with a triangular waveform signal at the switching frequency to generate switching functions.

For an induction motor with an isolated neutral

$v_{a}(t)+v_{b}(t)+v_{c}(t)=0$

To synthesize an average space vector $\bar{v}_{s}$ with phase components $v_{a}, v_{b}$ and $v_{c}$ following relation can be stated as the ratio of $v_{\text {contr }}$ (control voltages) to $v_{S w}$ (the 
amplitude of the constant switching frequency triangular signal)

$\frac{v_{\text {contr }, a}}{v_{s w}}=\frac{v_{a}-v_{k}}{v_{d c} / 2}$

$\frac{v_{\text {contr }, b}}{v_{s w}}=\frac{v_{b}-v_{k}}{V_{d c} / 2}$

$\frac{v_{\text {contr, } b}}{v_{s w}}=\frac{v_{b}-v_{k}}{V_{d c} / 2}$

where,

$v_{k}=\frac{\max \left(v_{a}, v_{b}, v_{c}\right)+\min \left(v_{a}, v_{b}, v_{c}\right)}{2}$

\section{Vector CONTROLled Induction Motor DRIVE}

\section{A. Induction Motor Modeling}

The mathematical model of a three- phase squirrel cage induction motor in synchronous rotating reference frames is given by equation (10)-(13) as follows.

$\left[\begin{array}{c}v_{q s}^{e} \\ v_{d s}^{e} \\ v_{q r}^{e} \\ v_{d r}^{e}\end{array}\right]=\left[\begin{array}{cccc}R_{s}+L_{s} p & \omega_{s} L_{s} & L_{m} p & \omega_{s} L_{m} \\ -\omega_{s} L_{s} & R_{s}+L_{s} p & -\omega_{s} L_{m} & L_{m} p \\ L_{m} p & \left(\omega_{s}-\omega_{r}\right) L_{m} & R_{r}+L_{r} p & \left(\omega_{s}-\omega_{r}\right) L_{r} \\ -\left(\omega_{s}-\omega_{r}\right) L_{m} & L_{m} p & -\left(\omega_{s}-\omega_{r}\right) L_{r} & R_{r}+L_{r} p\end{array}\right]\left[\begin{array}{c}i_{q s}^{e} \\ i_{d s} \\ i_{q r}^{e} \\ i_{d r}^{e}\end{array}\right]$

(10)

$T_{e}=\frac{3}{2} \frac{P}{2} L_{m}\left(i_{q s^{i}}^{e}{ }_{d r}^{e}-i_{d s}^{e} i_{q r}^{e}\right)$

$\frac{d \theta_{r}}{d t}=\omega_{r}$

$T_{e}=J_{m} \frac{d \omega_{r}}{d t}+B_{m} \omega_{r}+T_{L}$

Where $v_{d s}^{e}, v_{q s}^{e}$ are d-q axis stator voltages respectively; $i_{d s}^{e}, i_{q s}^{e}, i_{d r}^{e}, i_{q r}^{e}$ are d-q axis stator currents and d-q axis rotor currents respectively; $R_{S}, R_{r}$ are the stator and rotor resistance per phase respectively; $L_{S}, L_{r}, L_{m}$ are the self inductances of the stator and rotor and the mutual inductance respectively; $P$ is the number of poles; $p$ is the differentiation operator $(d / d t) ; \omega_{e}, \omega_{r}$ are the speed of the rotating magnetic field and the rotor speed respectively; $T_{e}, T_{L}$ are the electromagnetic developed torque and the load torque respectively; $J_{m}$ is the rotor inertia; $B_{m}$ is the rotor damping coefficient and $\theta_{r}$ is the rotor position.

The transformation from abc to $\mathrm{dq} 0$ variables is given by equation (14).

$f_{d q 0}=\left[T_{a b c}^{e}\right] f_{a b c}^{e}$

$$
\left[T_{a b c}^{e}\right]=\frac{2}{3}\left[\begin{array}{ccc}
\cos (\omega t) & \cos \left(\omega t-\frac{2 \Pi}{3}\right) & \cos \left(\omega t+\frac{2 \Pi}{3}\right) \\
\sin (\omega t) & \sin \left(\omega t-\frac{2 \Pi}{3}\right) & \sin \left(\omega t+\frac{2 \Pi}{3}\right) \\
\frac{1}{2} & \frac{1}{2} & \frac{1}{2}
\end{array}\right]
$$

where $\left[T_{a b c}^{e}\right]$ is transformation matrix given by equation (15) and $f$ may represents current or voltage.

\section{B. Vector Control}

For high performance drive system response, the vector controlled induction motor is a very accepted method. It is based on the decoupling of flux and torque producing components of the stator current. Under this condition, the $\mathrm{q}$-axis component of rotor flux is set to zero while the d-axis reaches the nominal value of the magnetizing flux. The torque equation can also be written as

$T_{e}=\frac{3}{2} \frac{P}{2} \frac{L_{m}}{L_{r}}\left(i_{q s}^{e} \lambda_{d r}^{e}-i_{d s}^{e} \lambda_{q r}^{e}\right)$

Since $\lambda_{q r}^{e}$ is zero

$T_{e}=\frac{3}{2} \frac{P}{2} \frac{L_{m}}{L_{r}}\left(i_{q s}^{e} \lambda_{d r}^{e}\right)=K_{t e} i_{q s}^{e} \lambda_{d r}^{e}$

where $K_{t e}=\frac{3}{2} \frac{P}{2} \frac{L_{m}}{L_{r}}=$ torque constant

If the rotor flux linkage in equation (17) is maintained constant, then the torque is simply proportional to the torque producing component of the stator current, as in the case of the separately excited dc machine with armature current control. The other field oriented controller equations are

$T_{r} \frac{d \lambda^{e} d r}{d t}+\lambda_{d r}^{e}=L_{m} i_{d s}^{e}$

$\omega_{e}=\frac{L_{m}}{T_{r}} \frac{i_{q s}^{e}}{\lambda_{d r}^{e}}+\omega_{r}$

$T_{r}$ denotes the rotor time constant. The equation (18) resembles the field equation in a separately excited dc machine, whose time constant is usually in the order of seconds. Likewise, the induction motor rotor time constant is in the order of seconds.

The equations which transform the synchronous reference frame to stationary reference frame are:

$i_{q s}^{s}=\cos \theta_{e} i_{q s}^{e}+\sin \theta_{e} i_{d s}^{e}$

$i_{d s}^{s}=-\sin \theta_{e} i_{q s}^{e}+\cos \theta_{e}^{i} e_{d s}^{e}$

where $i_{q s}^{s}, i_{d s}^{s}$ are stationary frame $\mathrm{q}$ and $\mathrm{d}$ axis stator current respectively.

\section{AdAPTIVE NEURO-FuZZY CONTROLLER}

The proposed neuro-fuzzy controller incorporates fuzzy 


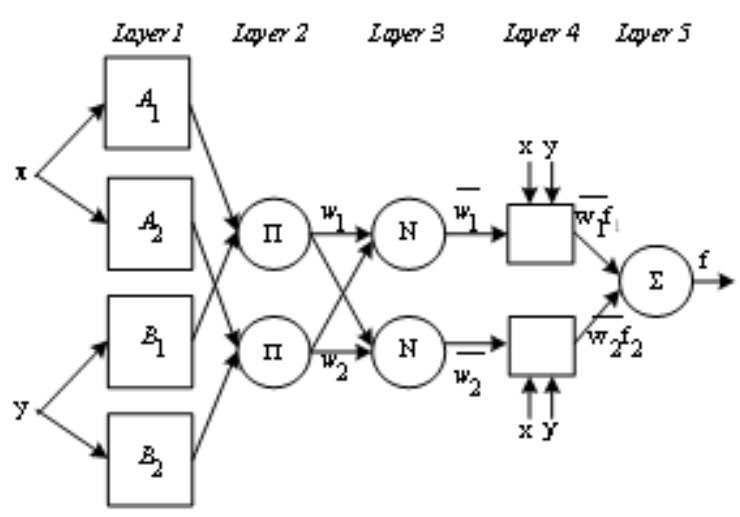

Figure.4 ANFIS architecture of 2-input Sugeno fuzzy model with 2 rules logic algorithm with a five layer artificial neural network (ANN) structure as shown in fig. 4.

A tuning block is utilized to adjust fourth layer's parameters in order to correct any deviation of control effort. The normalized speed error and the rate of change of actual speed error are the inputs of the neuro-fuzzy controller, which are given by

$$
\begin{aligned}
& \text { Input } 1=\varepsilon_{\omega}=\frac{\omega^{*}-\omega}{\omega^{*}} \times 100 \% \\
& \text { Input } 2=\Delta \varepsilon_{\omega}=\frac{\varepsilon_{\omega}(n)-\varepsilon_{\omega}(n-1)}{T} \times 100 \%
\end{aligned}
$$

where $\omega^{*}$ is the command speed and $T$ is the sampling time.

Sugeno fuzzy model with five- layer ANN structure is used in proposed controller. In this five-layer ANN structure the first layer represents for inputs, the second layer represents for fuzzification, the third and fourth layers represents for fuzzy rule evaluation and the fifth layer represents for defuzzification.

A two input first order Sugeno fuzzy model with two rules is depicted in fig. 4.

In layer 1 , every node $i$ is an adaptive node with a node function

$O_{1, i}=\mu_{A i}(x)$ for $i=1,2$ or

$O_{1, i}=\mu_{B i-2}(y)$ for $i=3,4$

(here we denote the output of the ith node in layer $\ell$ as $O_{\ell, i}$ )

where $\mathrm{x}$ (or y) is the input to node $i$ and $A_{i}\left(\right.$ or $B_{i-2}$ ) is a linguistic label such as 'small' or 'large' associated with this node. The membership function for $A$ can be any appropriate parameterized membership function. In proposed scheme generalized bell function is used as a membership function given by equation (25).

$$
\mu_{A}(x)=\frac{1}{1+\left|\frac{x-c_{i}}{a_{i}}\right|^{2 b i}}
$$

where $\left\{a_{i}, b_{i}, c_{i}\right\}$ is the parameter set. As the values of these parameters changes, various forms of bell shaped membership functions can be get for fuzzy set $A$. Parameters in this layer are referred to as premise parameters.
In layer 2 , every node is a fixed node labeled $\Pi$, whose output is the product of all the incoming signals.

$$
O_{2, i}=w_{i}=\mu_{A i}{ }^{(x)} \mu_{B i}{ }^{(y)}, i=1,2
$$

Each node output represents the firing strength of a rule.

In layer 3 , every node is a fixed node labeled $N$. The outputs of this layer are normalized firing strengths given by equation (27).

$$
O_{3, i}=\overline{w_{i}}=\frac{w_{i}}{w_{1}+w_{2}}, i=1,2
$$

In layer 4 , every node $i$, is an adaptive node with a node function given by equation (28).

$O_{4, i}=\overline{w_{i}} f_{i}=\overline{w_{i}}\left(p_{i} x+q_{i} y+r_{i}\right)$

where $\bar{w}_{i}$ is a normalized firing strength from layer 3 and $\left\{p_{i}, q_{i}, r_{i}\right\}$ is the parameter set of this node. Parameters in this layer are referred to as consequent parameters.

Layer 5 is the single node layer with a fixed node labeled $\Sigma$, which computes the overall output as the summation of all incoming signals.

$$
O_{5,1}=\sum_{i} \bar{w}_{i} f_{i}=\frac{\sum_{i} w_{i} f_{i}}{\sum_{i} w_{i}}
$$

Hybrid learning algorithm is used in proposed controller. In the forward pass of the hybrid learning algorithm, node output goes forward until layer four and the consequent parameters are identified by the least squares method. In the backward pass, the error signals propagate backward and premise parameters are updated by gradient descent. The consequent parameters thus identified are optimal under the condition that the premise parameters are fixed. Thus, the hybrid approach converges much faster since it reduces the search space dimension of the original pure back propagation.

The propose ANFIS had following features: TypeSugeno; AndMethod- product; OrMethod- probor (probabilistic or); DefuzzMethod- wtaver (weighted average); ImpMethod (implication method)- product; AggMethod (aggregation method)- sum; No. of input- 2; No. of input membership function- 3 ; input membership function typegbellmf (generalized bell curve membership function); No. of output- 1; No. of output membership function- 9; output membership function type - linear; No. of rules- 9. Fig. 5. presents proposed equivalent ANFIS architecture. Fig. 6. and Fig. 7. shows input membership functions and output surface of proposed ANFIS respectively. 


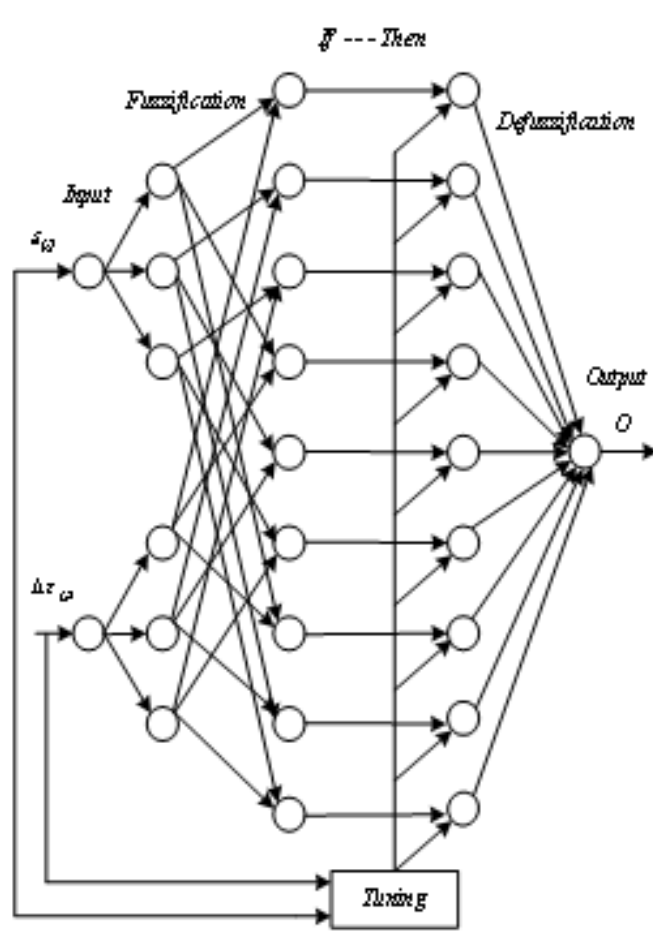

Figure.5 Proposed equivalent ANFIS architecture.
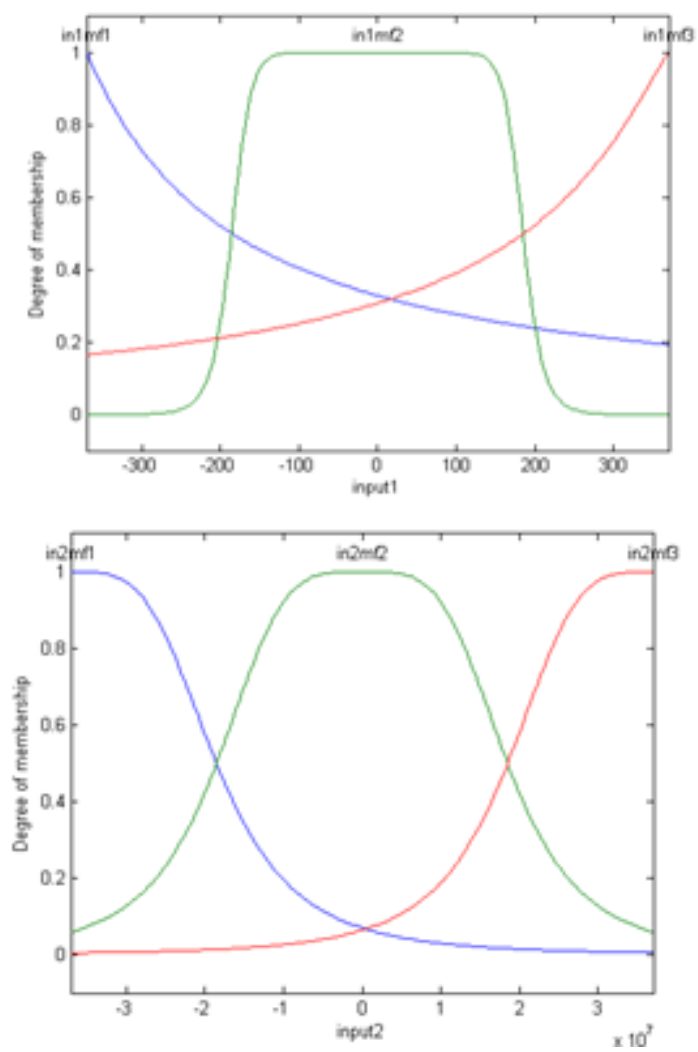

Figure.6 Input membership function of proposed ANFIS.

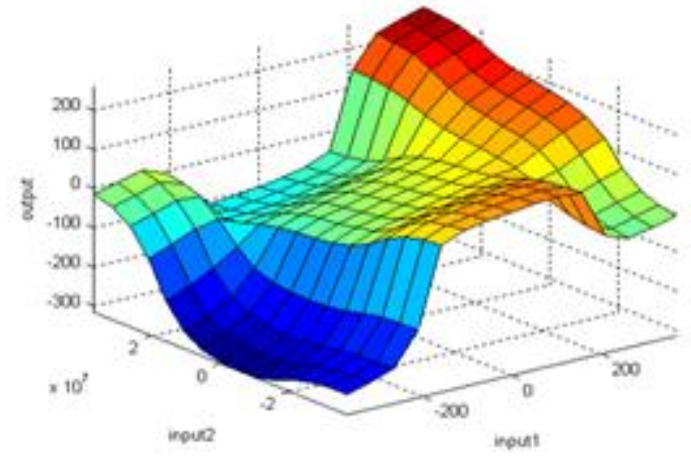

Figure.7 Output surface of proposed ANFIS.

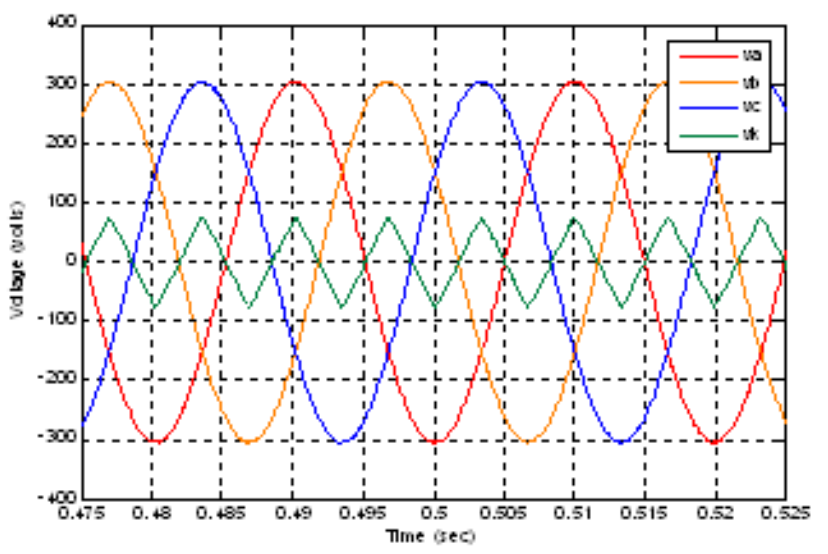

(a)

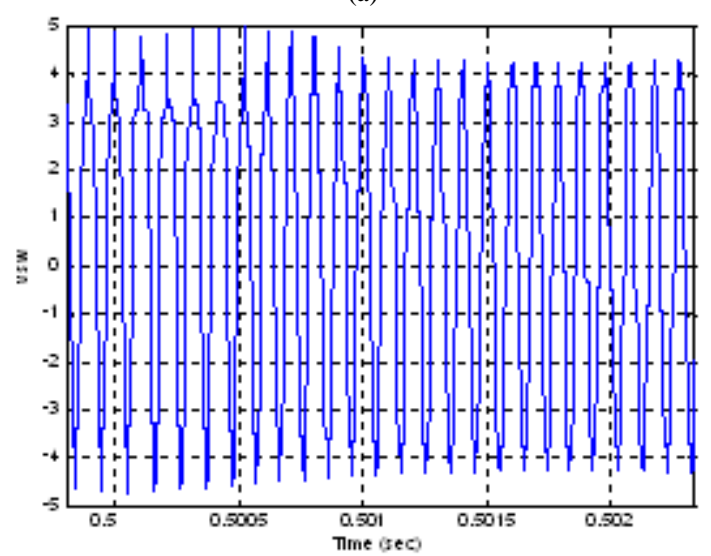

(b)

Figure.9 SVPWM waveforms (a) Phase components va, vb, vc and vk (b) vsw

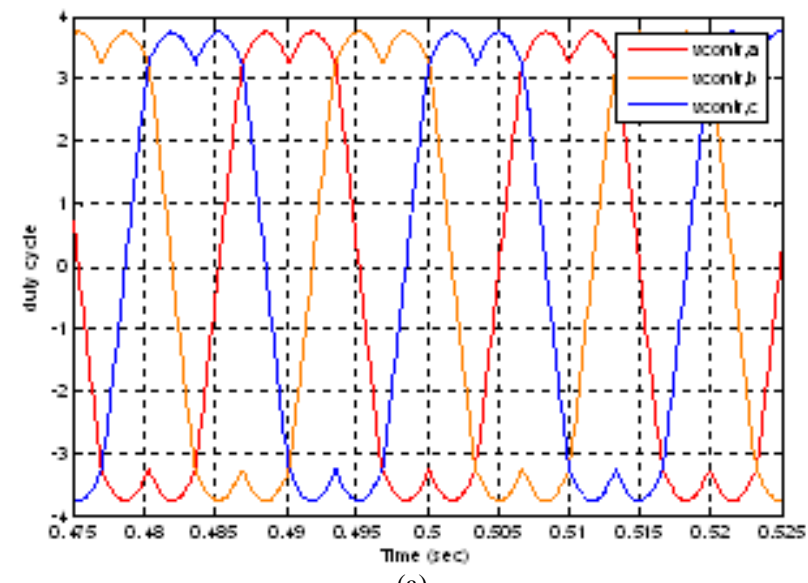

(a) 

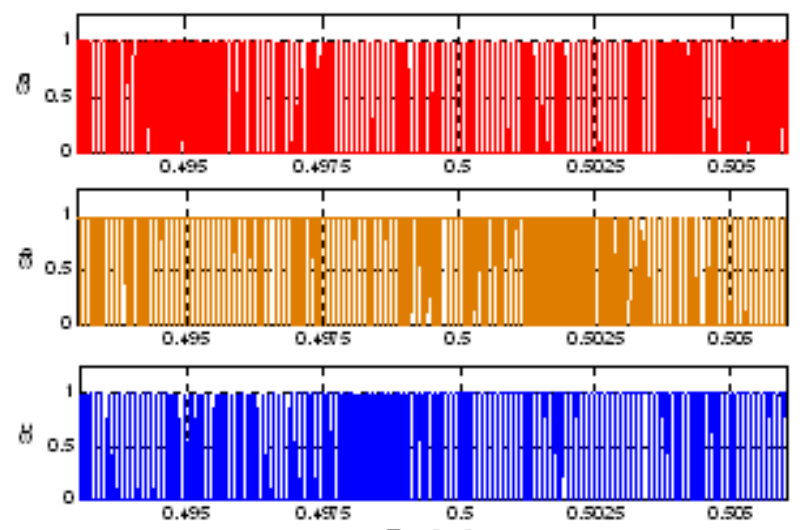

(b)

Figure.10 SVPWM waveforms (a) duty cycle (b) switching function

\section{PERformance ASSESSMENT OF NEURO-FUZZY} CONTROLLER BASED SVPWM-VCIM DRIVE

A complete simulation model for SVPWM-VCIM drive incorporating the proposed NFC is developed as shown in Fig. 8. The performance of the proposed NFC based SVPWM-VCIM drive is investigated at different operating conditions. In order to prove the superiority of the proposed NFC, a comparison is made with the response of conventional PI speed controller based VCIM drive. The parameters of the induction motor and SVPWM considered in this study are summarized in Appendix. Fig. 9. shows waveforms of $v_{a}, v_{b}, v_{c}, v_{k}$ and $v_{s w}$ for SVPWM. Fig. 10. shows waveforms of duty cycle $\left(v_{\text {contr, } a}, v_{\text {contr, } b}, v_{\text {contr,c }}\right)$ and switching function ( $S_{a}, S_{b}, S_{c}$ ) for SVPWM. The performance of SVPWM-VCIM drive with NFC is presented during starting, load perturbation and speed reversal. Transient, steady state and dynamic behavior of the drive with PI speed controller is shown in Fig. 11. and with neuro-fuzzy speed controller is shown in Fig. 12. The reference speed is set at $185 \mathrm{rad} / \mathrm{sec}$. The electromagnetic torque Te raises to maximum during starting of the motor from standstill and then settles down over remaining period (steady state condition). Same is for currents. At steady state load torque $T_{L}$ has been increased to $12 \mathrm{Nm}$ from $3 \mathrm{Nm}$ at time $\mathrm{t}=0.3 \mathrm{sec}$. and suddenly decreased to $3 \mathrm{Nm}$ at $\mathrm{t}=0.5 \mathrm{sec}$. Finally the motor that is operating at $185 \mathrm{rad} / \mathrm{sec}$, suddenly its reference speed is changed to negative $185 \mathrm{rad} / \mathrm{sec}$. Table II, III and IV presents performance comparison during steady state operation, during transient operation and in time domain analysis respectively. The results shows better performance of NFC based IM drive as compare to conventional PI controller based IM drive under starting, load perturbation and speed reversal. It shows NFC based SVPWM-VCIM drive is robust for high performance IM drive.

TABLE II

Performance comparison during steady state operation

\begin{tabular}{|c|c|c|}
\hline Controller & Speed Ripple (rad/sec) & Torque Ripple (Nm) \\
\hline PI & 0.1 & 0.0017 \\
\hline NFC & 0.004 & 0.0003 \\
\hline \multicolumn{3}{|c}{ TABLE III }
\end{tabular}

PERFORMANCE COMPARISON DURING TRANSIENTS

\begin{tabular}{|c|c|c|c|c|}
\hline Controller & $\begin{array}{c}\text { Starting } \\
\text { Time } \\
(\mathrm{sec} .)\end{array}$ & $\begin{array}{c}\text { Reversal } \\
\text { Time } \\
(\mathrm{sec} .)\end{array}$ & $\begin{array}{c}\text { Dip in } \\
\text { Speed } \\
(\mathrm{rad} / \mathrm{sec})\end{array}$ & $\begin{array}{c}\text { Rise in } \\
\text { Speed } \\
(\mathrm{rad} / \mathrm{sec})\end{array}$ \\
\hline PI & 0.04 & 0.145 & 4.9 & 4.8 \\
\hline NFC & 0.03 & 0.08 & 4.7 & 4.6 \\
\hline \multicolumn{5}{|c}{ TABLE IV }
\end{tabular}

PERFORMANCE COMPARISON IN TIME DOMAIN ANALYSIS

\begin{tabular}{|c|c|c|c|c|}
\hline Controller & $\begin{array}{c}\text { Peak } \\
\text { Over } \\
\text { shoot }\end{array}$ & $\begin{array}{c}\text { Peak } \\
\text { Time } \\
(\mathrm{sec} .)\end{array}$ & $\begin{array}{c}\text { Rise } \\
\text { Time } \\
(\mathrm{sec} .)\end{array}$ & $\begin{array}{c}\text { Settle } \\
\text { Time } \\
(\mathrm{sec} .)\end{array}$ \\
\hline PI & 0.1351 & 0.06 & 0.03 & 0.13 \\
\hline NFC & 0.0054 & 0.057 & 0.026 & 0.11 \\
\hline
\end{tabular}

\section{CONCLUSION}

A novel Neuro-fuzzy controller based SVPWM-VCIM drive has been presented in this paper. Some of the advantages of ANFIS are reduced number of rules, faster speed of operation and no need for modifications in membership function by conventional trial and error method for optimal response. This makes NFC a easy-build and robust controller. The performances of the proposed NFC based SVPWM-VCIM drive has been investigated at various operating conditions. A comparison of the performance between the proposed NFC based drive and PI based drive has also been presented. The proposed NFC based SVPWM-VCIM drive has been found to be robust for high performance drive application.

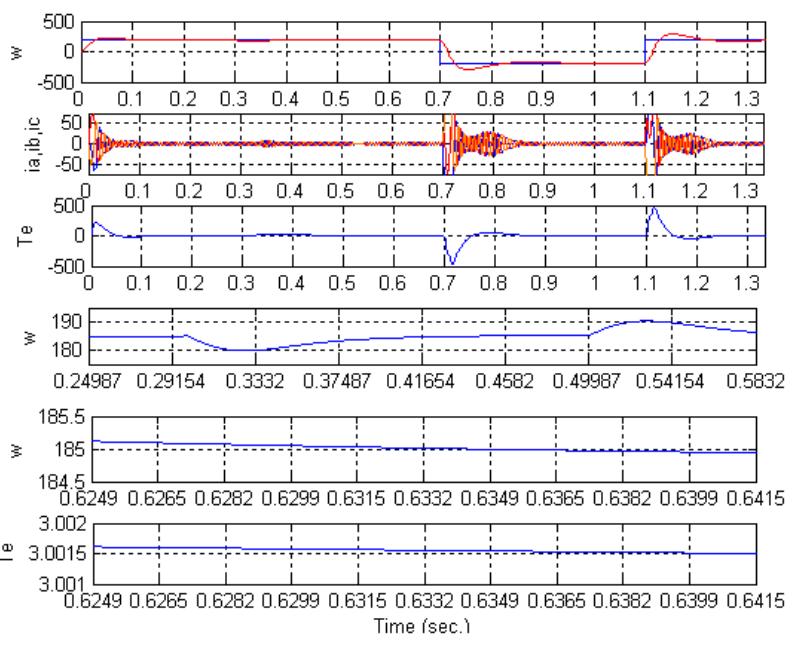

Figure.11 Performance Characteristics of Drive Scheme with PI- Speed controller (a) speed (rad/sec.) (b) current (amp.) (c) torque (Nm) (d) speed during loading cycle (e) speed ripples (f) torque ripples. 

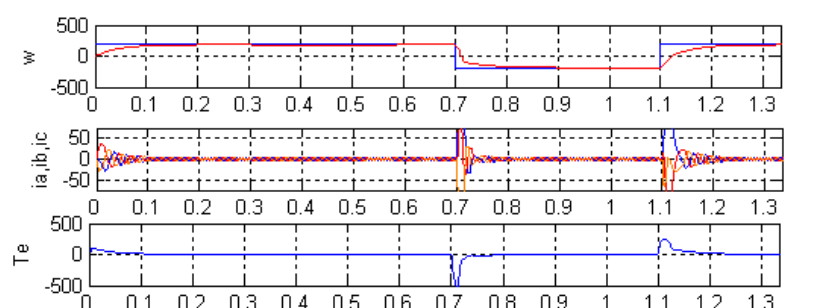

$3 \begin{aligned} & 190 \\ & 180\end{aligned}$ $\begin{array}{lllllllll}0.24987 & 0.29154 & 0.3332 & 0.37487 & 0.41654 & 0.4582 & 0.49987 & 0.54154 & 0.5832\end{array}$

\begin{tabular}{rl|l|l|l|l|l|l|l|l|l|} 
& 185.5 \\
\hline & & & & & & & & & & \\
\hline & & & & & & & & & \\
\hline
\end{tabular}

$184.5 \quad 0.62490 .62650 .62820 .62990 .63150 .63320 .63490 .63650 .63820 .63990 .6415$

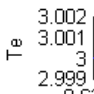

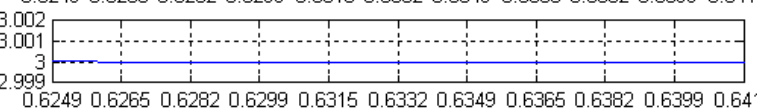
Time (sec.)

Figure.12Performance Characteristics of Drive Scheme with ANFIS- Speed controller (a) speed (rad/sec.) (b) current (amp.) (c) torque (Nm) (d) speed during loading cycle (e) speed ripples (f) torque ripples.

\section{APPENDIX}

The parameters of induction motor are as follows:

\section{REFERENCES}

[1] Ned Mohan, Advanced electric drives analysis, control and modeling using Simulink. MNPERE Minneapolis, USA.

[2] Rajesh Kumar, R. A. Gupta, and Bhim Singh, "Intelligent Tuned PID Controllers for PMSM Drive -A Critical Analysis", in the Proc. of IEEE International Conference on Industrial Technology (ICIT2006),Mumbai, INDIA, pp. 2055-2060.

[3] Z. Ibrahim and E. Levi, "A comparative analysis of fuzzy logic and PI speed control in high-performance AC drives using experimental approach," IEEE Transl. On Ind. Appli, vol. 38, No.5, pp. 1210-1218, Sep/Oct. 2002.

[4] M.V. Aware, A.G. Kothari and S.O. Choube, "Application of adaptive neuro-fuzzy controller (ANFIS)for voltage source inverter fed induction motor drive," in the Proc. of IPEMC 2000 Conf., Vol. 2, 15-18 Aug 2000 pp. 935-939.

[5] Tae-Chon Ahn, Yang-Won Kwon, Hyung- Soo Hwang and Pedrycz, W, "Design of neuro-fuzzy controller on DSP for real-time control of induction motors," in the Proc. of NAFIPS 2001 Conf., Vol. 5, 25-28 July 2001, pp. 3038-3043.

[6] M. N. Uddin and H. Wen "Development of a self-tuned neuro-fuzzy controller for induction motor drives," in Conf. record of Industry Applications 2004, Vol. 4, 3-7 Oct. 2004, pp. 2630-2636.

[7] P. P. Cruz, J. M. Aquino and M. R. Elizondo, "Vector control using ANFIS controller with space vector modulation [ induction motor drive application]," in the Proc. of UPEC 2004 Conf., Vol. 2, 6-8 Sept. 2004, pp. 545-549.

[8] A. Miloudi, E.A.A Radadi, A. Draou and Y. Miloud, "Simulation and modeling of a variable gain PI controller for speed control of a direct torque neuro fuzzy controlled induction machine drive," in the Proc. of IEEE PESC 2004 Conf., Vol. 5, 20-25 June 2004, pp. 3493-3498.

[9] Zhi Rui Huang and M.N. Uddin, "Development of a simplified Neuro-Fuzzy controller for an IM drive," in the Proc. Of IEEE International Conf. on Industrial Technology 2006 , 15-17 Dec. 2006, pp. 63-68.

[10] M. N. Uddin Z. R. Huang and Md. M. Chy "A simplified self-tuned neuro-fuzzy controller based speed control of an induction motor drives," in the Proc. Of PES General Meeting 2007, 24-28 June. 2007, pp. 1-8.

[11] Matlab, Simulink user guide, The Math Works Inc., 2003.

[12] J.S.R. Jang, C.T. Sun and E. Mizutani, "Neuro-Fuzzy and soft computing- A computational approach to learning and machine intelligence", Prentice-Hall of India Pvt. Ltd., New Delhi, 2006.

$\begin{array}{cll}P & \text { Nominal power } & 2.2 \mathrm{KW} \\ R_{s} & \text { Stator resistance } & 1.77 \mathrm{ohms} \\ R_{r} & \text { Rotor resistance } & 1.34 \mathrm{ohms} \\ X_{l s} & \text { Stator leakage reactance } & 5.25 \mathrm{ohms} \\ X_{l r} & \text { Rotor leakage reactance } & 4.57 \mathrm{ohms} \\ X_{m} & \text { Mutual reactance } & 139 \mathrm{ohms} \\ J & \text { Rotor inertia } & 0.025 \mathrm{Kg} \cdot \mathrm{m}^{2} \\ p & \text { Number of pole } & 4\end{array}$

The parameters for SVPWM:

$\begin{array}{lll}v_{d c} & \text { DC-link voltage } & 700 \text { volts } \\ v_{s w} & \begin{array}{l}\text { Amplitude of } \\ v_{s w} \text { voltage }\end{array} & 5 \text { volts } \\ f_{s w} & \text { Switching frequency } & 10 \mathrm{kHz}\end{array}$

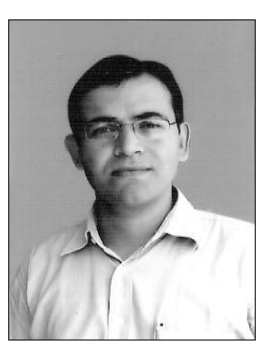

Rajesh Kumar received the B.Tech. degree in Electrical Engineering from the National Institute of Technology (NIT), Kurukshetra, India in 1994, the M. E. degree in Electrical Engineering from the Malaviya National Institute of Technology (MNIT), Jaipur, India in 1997 and the Ph.D. degree in Intelligent systems from University of Rajasthan, India in 2005. In 1995 he joined as Lecturer with the Department of Electrical Engineering, MNIT, Jaipur and now working as Reader at the same institute. His research interests include Intelligent Control, Evolutionary Algorithms, Fuzzy and Neural methodologies, Power Electronics and drives. Dr. Kumar received the Career Award for Young Teachers (CAYT) from Govt. of INDIA in 2002. He is a member of IEEE, fellow of IETE, member of Institute of Engineers (INDIA) and life member of Indian Society for Technical Education (ISTE). He has published more than 100 research publications in various National, International Conferences, proceedings and Journals.

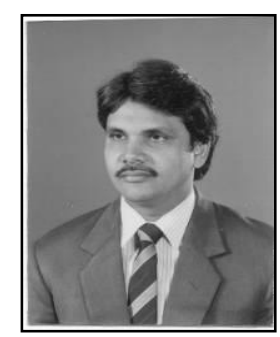

R. A. Gupta was born in Chandera, Rajasthan, India, in 1956. He received B.E. (Electrical) and M.E. Degrees from the University of Jodhpur, India in 1980 and 1984, respectively and Ph.D in 1994 from IIT, Roorkee, India. In 1982, he joined as an Assistant Professor in the Department of Electrical Engineering, University of Jodhpur. In November 1990, he joined as a Reader and become full Professor in 1999 at the Department of Electrical Engineering, MREC, Jaipur (INDIA). His field of interest includes power electronics, electrical machines and drives. Prof. Gupta is a fellow of Institute of Engineers (INDIA), member of IEEE, a life member of (ISTE) and Indian Society for continuing Engineering Education.

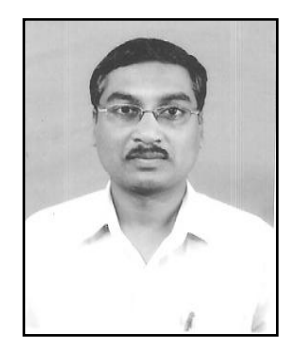

Rajesh S Surjuse received the B.E. and M.Tech. degree in electrical engineering from the Visvesvaraya National Institute of Technology (VNIT), Nagpur, India in 1994 and 2003 respectively. In 1995, he joined as Lecturer with the Department of Electrical Engineering, Govt. Polytechnic Yavatmal, India and now working as a senior Lecturer in the Department of Electrical Engineering, Govt. Polytechnic Nagpur, India. He is a student member of IEEE, member of IACSIT and life member of Indian Society for Technical Education (ISTE). At present he is research scholar at Malaviya National Institute of Technology (MNIT) Jaipur, India.. His primary area of research includes Power Electronics and Electrical Drives and control. 
International Journal of Computer and Electrical Engineering, Vol. 2, No. 1, February, 2010 $1793-8163$

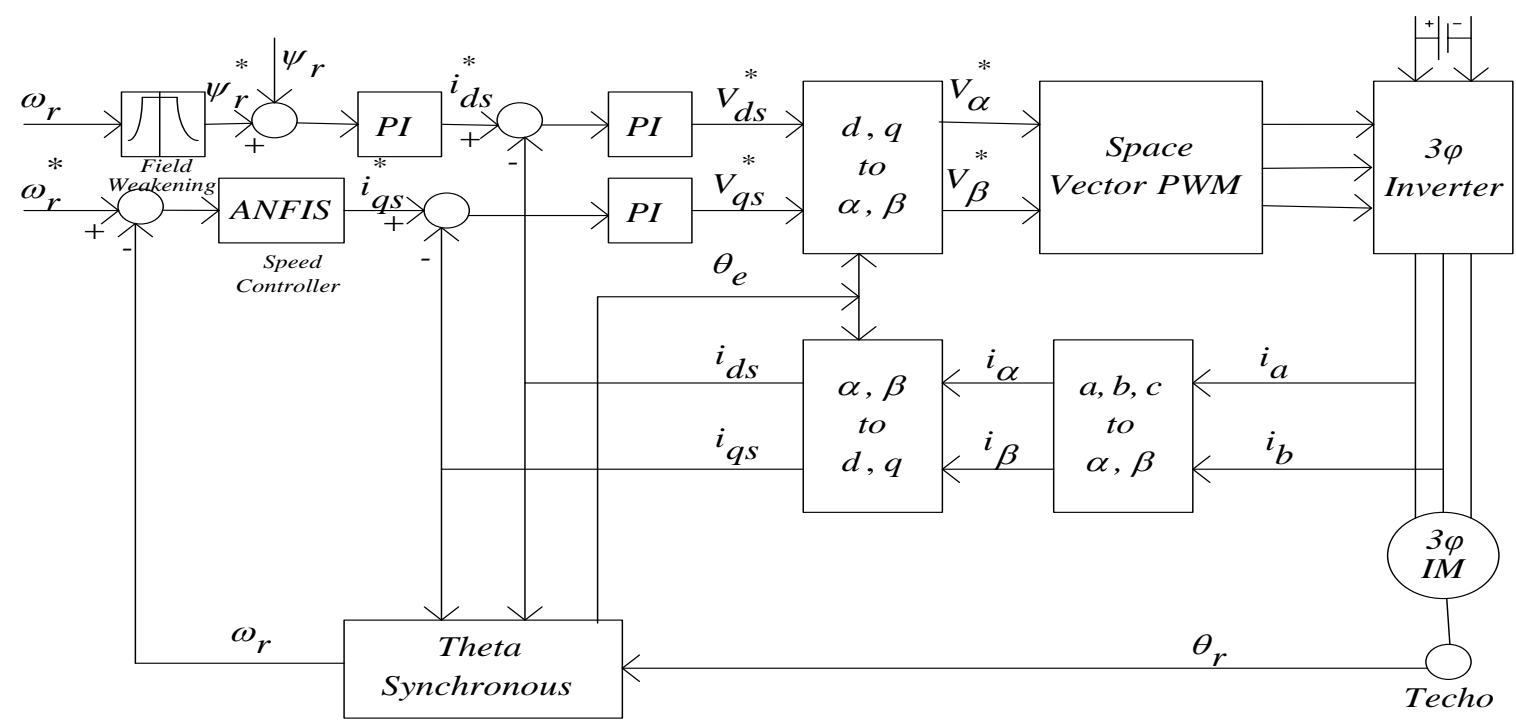

Figure.8 Adaptive Neuro-Fuzzy speed controller based vector controlled induction motor drive. 